\section{Professionalism}

\section{highlighted}

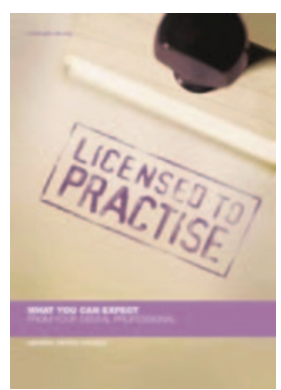

The General Dental Council (GDC) has produced a new leaflet for dental patients to highlight the professionalism of the dental team. 'Licensed to Practise' was launched at the Citizens Advice annual conference earlier this month, and explains the high standards patients can expect from the professionals who provide their dental care. It also offers advice on the sorts of questions patients should ask themselves when considering dental treatment.

According to Antony Townsend, GDC Chief Executive and Registrar, the aim of the leaflet is to help recognise the professionalism of the members of the dental team and help boost patient confidence. The leaflet has been introduced as a pilot to begin with and the GDC will be writing to a sample of dentists directly to offer them bulk copies for their practices.

Dental professionals who would like multiple copies of the leaflet, free of charge, for their workplace can call the GDC on 02078873824 or email communications @gdc-uk.org. It has been awarded the Plain English Campaign's Crystal Mark for clarity and will soon be available in Urdu, Hindi and Welsh.

\title{
Child protection training for dentists launched
}

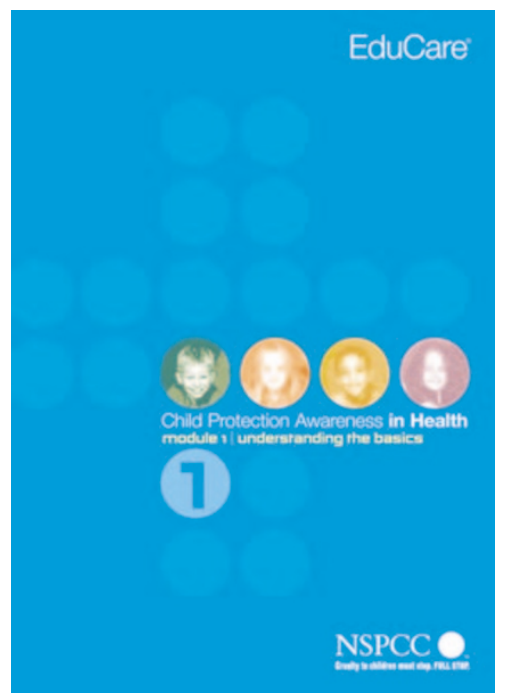

Dentists and their support staff are to be targeted as part of the NSPCC's biggest ever child protection training exercise. From 3 October 2005, dental surgeries across the country will have received complimentary copies of EduCare, a child protection awareness distance learning programme.

The mailing is part of the NSPCC's latest initiative, 'Talk 'til it stops', a campaign designed to mobilise people to take action to end child abuse. The campaign will encourage people to talk to each other if they are worried about a child. The organisation claims that dentists can be a vital link in the child protection chain as they have frequent contact with children and families. EduCare will help dental staff recognise the possible signs of abuse and ensure they know how to act if they have concerns about a child. The programme will also help staff act appropriately if a patient approaches them with child protection concerns.

NSPCC Director and Chief Executive Mary Marsh said, "Everyone who works for or alongside children and young people must be able to recognise, respond and report any concerns they have about a child. Even professionals who have had child protection training should take this opportunity to remind themselves who the child protection leads are in their organisation and what they should do if they are worried about a child being abused."

EduCare consists of four short learning modules and is tailored for specific sectors. Recipients will receive module one which includes the learning materials and a short multiple-choice questionnaire. Participants simply read through the module, complete the questionnaire and send it off in a reply-paid envelope to be marked. As well as dentists, over 220,000 copies of the EduCare learning programme will be mailed to key groups including school and practice nurses and GPs and the police and the fire service.

There are limited complimentary copies of EduCare available for anyone working with children and young people, but who have not been included in the mailing. If you would like to be part of this programme, simply register online at www.debrus-educare.co.uk /talktilitstops or e-mail your name, address and job title to talktilitstops@debrus.co.uk or telephone 01926 436202. Applicants will be processed on a first come, first served basis.

See the book review on page 11 and our article on page 23 .

\section{Name change}

Professionals complementary to dentistry (PCDs) will now be collectively known as dental care professionals (DCPs). The name change was agreed by the GDC at its September meeting, and applies to dental hygienists, dental therapists, and the four groups of professionals who will start registering with the General Dental Council (GDC) for the first time in July 2006. These are dental nurses, dental technicians, clinical dental technicians and orthodontic therapists. The change has been made in order to be consistent with terminology used in the Dentists Act which was recently amended to give the GDC a range of new powers, including the power to start registering other dental team members.

Hew Mathewson, President of the General

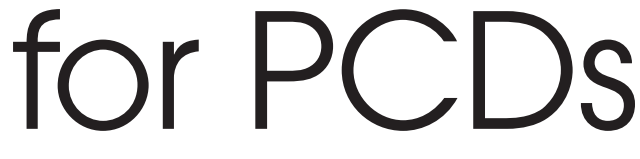

Dental Council said, "The term 'dental care professional' sums up the important role these members of the dental team play in patient care. The name change does not affect the respective titles of the individual professions - a dental hygienist, will still be known as a dental hygienist, and a dental nurse will still be a dental nurse." For more information about DCP registration visit www.gdc-uk.org 